\title{
CHANGES IN CANADIAN FAMILY INCOME AND FAMILY CONSUMPTION INEQUALITY BETWEEN 1978 AND 1992
}

\author{
By Krishna Pendakur \\ Simon Fraser University
}

\begin{abstract}
This paper uses Canadian cross-sectional income and expenditure data to examine changes in the distribution of family income and family consumption during the period 1978 to 1992 . Family consumption data are analyzed because in the presence of intertemporal consumption smoothing, the cross-sectional distribution of consumption may characterize the distribution of lifetime wealth. I find that both Canadian family income inequality and Canadian family consumption inequality moved countercyclically. In addition, both Canadian family income inequality and Canadian family consumption inequality trended upward over the period; however, the change in family consumption inequality was much smaller than the change in family income inequality, suggesting that inequality in the distribution of lifetime wealth may have changed much less than is suggested by changes in the distribution of income.
\end{abstract}

\section{INTRODUCTION}

This paper investigates both the trend and the cyclical variability of economic inequality across families in Canada during the period 1978 to 1992 . I look at inequality in both the distribution of family income and the distribution of family consumption. While the literature usually focuses on the distribution of family income, I also analyse the distribution of family consumption because, when certain restrictions are satisfied, cross-sectional data on the distribution of family consumption allow a close view of the real object of interest: the distribution of lifetime wealth.

I find that Canadian family income inequality and family consumption inequality were both strongly countercyclical between 1978 and 1992. Both became more unequal during the two recessions in the sample period, and both equalized during the intervening period of growth. Further, Canadian family income inequality and Canadian family consumption inequality both trended upward over the period. However, family income inequality rose faster than family consumption inequality. Between the pre-recession years of 1978 and 1990, the Gini index of family income inequality increased more than three percentage points, while the Gini index of family consumption inequality increased by less than one percentage point. By comparison, recent research on economic inequality in the U.S.A. (Cutler and Katz, 1992) found that over a similar period, the Gini index of American family income inequality rose by three percentage points, while the Gini index of American family consumption inequality rose by two percentage

Note: I wish to acknowledge the financial support of the Fulbright Foundation and of the Social Sciences and Humanities Research Council of Canada. I also wish to thank William Dickens, David Donaldson, Greg Dow, Steve Easton, Curt Eaton, Diane Eaton, Hilary Hoynes, Clyde Reed, Michael Reich, John Wald and one anonymous referee for comments and discussion. Mistakes that remain are of course my own. 
points. Thus, inequality in the distribution of family income increased by about the same amount in the two countries, but inequality in the distribution of consumption increased more in the U.S.A. than in Canada. This suggests that the distribution of lifetime wealth may have widened more in the U.S.A. than in Canada over the 1980s.

\section{Consumption, Income and Wealth}

We may define the lifetime wealth of an individual $i, W_{i}$, as equal to total discounted lifetime income or total discounted lifetime consumption as follows:

$$
\begin{aligned}
W_{i} & \equiv A_{i}+\sum_{1}^{T} \frac{1}{(1+r)^{t}} y_{i t} \\
& \equiv \sum_{1}^{T} \frac{1}{(1+r)^{t}} c_{i t}+\frac{1}{(1+r)^{T}} B_{i}
\end{aligned}
$$

where $A_{i}$ is initial assets, $B_{i}$ is bequest at time $T, r$ is the interest rate, $y_{i t}$ is income in period $t$ and $c_{i t}$ is consumption in period $t$.

Equation (1) simply states an accounting identity: an agent's wealth is defined as discounted lifetime income (including initial assets), and it must equal discounted lifetime consumption (including bequests). Since wealth represents the lifetime budget constraint of an agent, it measures the opportunity set for consumption available to that agent. The distribution of wealth as defined by (1) should therefore be of major interest of researchers concerned with the distribution of economic opportunity. If panel data on either lifetime income or lifetime consumption (together with data on initial wealth or bequests) were available, a researcher could directly generate estimates of lifetime wealth. If we assume that utility depends only on consumption in each period and on bequests, then lifetime wealth estimated in this fashion will be an indicator of an agent's well-being. If we further assume that utility is comparable across agents, then information about the distribution of wealth will characterize the distribution of well-being across agents. Unfortunately, lifetime-length panel data on income is rare for countries other than the U.S.A., and, since data about the future income of the young do not exist, even the best panel data can only inform us about the lifetime income of the current elderly.

Cross-sectional consumption data may provide an alternative estimator of lifetime wealth without the use of panel data. Many researchers have noted that the Euler equation governing an agent's optimal intertemporal allocation of consumption specifies that agents must keep the marginal utility of consumption (suitably discounted for time preferences and interest rates) constant over time (see, for example, Browning and Lusardi, 1996). If we assume that credit markets are perfect and that utility functions are intertemporally additively separable, and denote the concave within-period utility function as $v(c)$, then the (full information) Euler equation for allocation between periods $t$ and $t+1$ is given by:

$$
v_{c}\left(c_{t}\right)=\beta(1+r) v_{c}\left(c_{t+1}\right)
$$


where utility is given by $U\left(c_{1}, \ldots, c_{T} ; B\right)=\sum_{1}^{T} \beta^{t} v\left(c_{t}\right)+z(B)$, agents are constrained to spend only discounted lifetime income as given by (1), $v_{c}$ is $\partial v(c) / \partial c$ (within-period marginal utility), and $\beta<1$ is the rate of time preference.

Equation (2) implies that the marginal rate of substitution across consecutive periods is equal to $\beta(1+r)$. Thus, if the rate of time preference balances the interest rate $(\beta=1 /(1+r))$, agents will choose consumption to equalize marginal utility across periods. They will choose a constant level of consumption that satisfies (1), and if agents do not derive utility from bequests $(z(\beta)=0)$, that consumption level is defined by $c=c_{t}=W /\left(\Sigma_{1}^{T} \beta^{t}\right)$. In this case, consumption is a perfect indicator of lifetime wealth, and we could therefore estimate wealth as $W=\left(\Sigma_{1}^{T} \beta^{t}\right) c$. As a result, cross-section data about consumption could be an alternative to panel data on income in measuring lifetime wealth, and it would have the advantage of being applicable to the current generation of young agents.

If $\beta>1 /(1+r)$, then marginal utility drops over time and consumption increases over time. Conversely, for $\beta<1 /(1+r)$, consumption decreases over time. In these situations we cannot estimate $W$ from consumption in any period unless we specify the forms of $v(c)$ and $z(B)$. Consumption will have a monotonically increasing or decreasing profile over time, and any addition to lifetime wealth (perhaps through $A_{i}$ ) will result in slightly higher consumption in every period. Thus, if two agents are the same age and have identical utility functions but different consumption levels, then the agent with the higher consumption level has higher lifetime wealth.' Thus, although we cannot estimate wealth from crosssectional consumption data in these situations (without specifying utility functions), we can order these two agents in terms of lifetime wealth.

We can go one step further towards characterizing the distribution of lifetime wealth if we assume that within-period subutility functions exhibit Constant Relative Risk Aversion (CRRA) and that agents do not derive utility from bequests. When an agent has CRRA preferences, then proportionate increases in lifetime wealth (given by (1)) lead to proportionate increases in consumption in every period. Thus, if two agents are the same age and have identical CRRA preferences, but one agent has twice the consumption of the other, then the agent with higher consumption has twice as much lifetime wealth.

Since consumption in any period is proportionately related to lifetime wealth, cross-sectional data on consumption would allow us to estimate the relative lifetime wealth of each agent. This feature is particularly useful when relative inequality indices are used to evaluate the distribution of consumption. The Gini Coefficient, S-Gini index family, and Atkinson index family are all examples of relative inequality indices which share the characteristic of invariance with respect to proportionate changes in the unit of analysis across agents. Formally, an inequality index, $I(x)$, which measures inequality in some variable, $x$, is relative if and only if the following condition holds (see, for example, Blackorby, Bossert, and Donaldson, 1995):

$$
I(\lambda x)=I(x)
$$

${ }^{1}$ I note that if agents have identical utility functions but are of different ages, then they might have different consumption levels even if they have the same lifetime wealth. The dependence of consumption on age (given wealth) only disappears if we assume that the rate of time preference exactly balances the interest rate. Unfortunately, the data used in this paper do not contain age data on all household members in all sample periods. 
where $x=\left\{x_{1}, \ldots, x_{N}\right\}$, a vector of population well-being variables, and $\lambda$ is an arbitrary scale factor.

Given CRRA preferences and identically-aged agents, the wealth of any agent is equal to that agent's consumption level multiplied by a constant which is the same for all agents. Thus, for any relative inequality index, such as the Gini Coefficient, the index value for the distribution of consumption is equal to the index value for the distribution of lifetime wealth.

To summarize, the model of consumption choices characterized by perfect information, perfect credit markets, and intertemporally additive utility suggests that cross-sectional data on consumption is useful in estimating the lifetime wealth of agents. This allows us to circumvent the requirement for lifetime panel data about agents' income or consumption in favour of cross-section data about agents' consumption. Further, consumption data may be used as an indicator of the lifetime wealth of the current generation of young agents, for whom data on future incomes are not available. If we are restricted to cross-sectional data, then consumption may have an advantage over income in estimating lifetime wealth because consumption levels are chosen by agents with lifetime wealth as a constraint.

Although it is natural to think of the individual as the agent for generating income, the natural agent in setting consumption levels is as likely to be the family. Further, the theory of household production suggests that the family should be the unit of analysis for income and consumption, partly because many goods such as housing and transportation may be intra-family public goods. In this paper, I use the family as the unit of analysis for investigations into the distributions of income and consumption.

\section{Previous Research}

Research on individual income distributions has found increasing individual income and wage inequality in many industrialized countries over the 1980s, including Canada, the U.S., the U.K. and Sweden (see, Abraham and Houseman, 1993; Atkinson, 1993; Buhmann et al., 1987; Davis, 1992; and Wolfson, 1994). This body of research has also found that individual income inequality tends to move countercyclically, so that recession years are characterized by relatively high levels of individual income inequality (for Canada, see Buse, 1982; for the U.S.A., see Beach, 1977).

Compared to research on individual income inequality, the distribution of family income in developed countries has been understudied. While individual income distributions were growing more unequal in most industrialized countries, it seems that family income distributions have been changing in a less uniform fashion across countries. Atkinson (1993) suggests that over the 1980s, family income inequality rose in some countries (for example, the U.S. and U.K.), and fell in others (for example, the Netherlands and Portugal (see also Gouveia and Tavares, 1995)). Several American studies (see Karoly, 1992; Cutler and Katz, 1992; and Blackburn and Bloom, 1994) suggest that inequality in family income has increased significantly in the U.S. over the 1980s. 
Research on family income inequality in Canada has found changing patterns over time. Wolfson (1987), who analysed family income data from the Surveys of Consumer Finance, found increasing inequality over the 1960s, decreasing inequality over the 1970 s and again increasing inequality in the early $1980 \mathrm{~s}$. McWatters and Beach (1990), who examined Statistics Canada's grouped income data, found that the ratio of the top to bottom quintile shares of family income increased over the period 1980-84, and decreased over the period 1984-87, suggesting countercyclical family income inequality. Blackburn and Bloom (1994), who analysed microdata from the Surveys of Consumer Finance, found that total family income inequality was about the same in 1987 as it was in 1979 . The research on Canadian family income inequality also found that the distribution of net family income had changed comparably little in terms of inequality. The present paper uses data from the Family Expenditure Surveys and corroborates Wolfson's finding of increasing family income inequality in the early to mid 1980s, and extends our knowledge of family income inequality to 1992. I find that family gross income inequality and net income inequality fell somewhat between 1986 and 1990 and then rose again in the 1992 recession.

The distribution of family consumption has only been studied in the U.S.A., Portugal and Canada. Family consumption inequality has evolved differently in these three countries. Gouveia and Tavares (1995) found that in Portugal between 1980 and 1990 household consumption became more equally distributed. On the other hand, Cutler and Katz (1992) found that American family consumption became much less equally distributed over a similar period, from 1980 to 1988 . Although Barrett and Pendakur (1995) suggest that in Canada the distribution of nondurable family consumption narrowed over the 1982-90 period, they do not measure changes in the distribution of total consumption (which would include the consumption flow from durable goods). The present paper finds that once an adjustment is made for the imputed consumption flows from durable goods, family consumption inequality in Canada seemed to move countercyclically. The distribution of family consumption became less equal over 1978 to 1986 , more equal between 1986 and 1990, and less equal between 1990 and 1992. In addition, the distribution of Canadian family consumption seems to have followed a slow disequalizing trend; consumption was slightly more unequally distributed in 1990 (a pre-trough year) than it was in 1978 (another pre-trough year).

The results from the present paper contrast with findings for American consumption inequality. In the U.S.A., both the family income and family consumption distributions became much more unequal over the 1980 s, but in Canada, the change in the family income distribution was much more pronounced than the change in the family consumption distribution. Further, while the distribution of consumption in Canada narrowed over the period of growth from 1986 to 1990 , the distribution of consumption in the U.S. seems to have widened over a similar period of growth during 1984 to 1988 (Cutler and Katz, 1992).

\section{The DATA}

This analysis uses the 1978, 1982, 1984, 1986, 1990 and 1992 Family Expenditure Surveys (FES). These surveys were conducted by Statistics Canada and collect 
information on demographics, income and expenditures from five to ten thousand Canadian households in each survey year (Statistics Canada, various years). The universe for these surveys varied from year to year: the 1978, 1982, 1986, and 1992 surveys sampled from all urban and rural households in the ten provinces of Canada, while the 1984 and 1990 surveys sampled only from urban households in Canada's 15 largest Census Metropolitan Areas (CMAs). To maximize the number of survey years available and to avoid imputing rural consumption, I analyse data on urban residents only, unless otherwise specified. ${ }^{2}$ There are 30,315 families in the final sample.

As noted above, if the rate of time preference balances the interest rate then consumption is invariant with age, and the distribution of lifetime wealth depends only on the distribution of consumption and does not depend on the age distribution. If these parameters do not balance, then consumption may vary over the life cycle of the agent, and the distribution of lifetime wealth may depend on both the consumption distribution and the age distribution. Unfortunately, the FES data do not contain age data on all family members in all survey years, so I do not control for age. ${ }^{3}$

The primary variables of interest in this paper are Gross Income, Net Income, Nondurable Consumption and Imputed Consumption. All variables are computed at the level of the economic family, with an adjustment for family size. ${ }^{4} \mathrm{An}$ economic family is defined as an unattached individual, or a group of people, related by blood, marriage or adoption, who live together in a household. Both income types are measures of total income, and thus include income from government transfers, as well as wages and salaries, self-employment and investment income. Net income excludes federal and provincial income taxes but includes sales and commodity taxes. Income from all family members is included in the income measures.

I define nondurable consumption as total expenditure less indirect savings and durable consumption. ${ }^{5}$ Four components are subtracted from total expenditure to get nondurable consumption. First, all investment is subtracted. Second, all life insurance and public and private pension payments are deducted, since these reflect deferred consumption. Third, spending on shelter is deducted, since for owner-occupier families these expenditures often represent savings

${ }^{2} \mathrm{CMA}$ indicators are not available in the 1978 and 1982 surveys, so for these years I use residents of cities with more than 100,000 persons (more than 30,000 persons in the Atlantic region). For all other years, I use residents of Canada's 15 largest CMAs, which is a strict subset of the cities used in the 1978 and 1982 data. As noted in Section VII and Table 6, the results of the paper do nt change much if $I$ use the larger set of cities in 1986 and 1992.

${ }^{3}$ Research on the distribution of consumption is prone to this sort of problem. Neither Cutler and Katz (1992) nor Gouveia and Tavares (1995) control for age, presumably for similar reasons.

${ }^{4}$ The 1978-86 Family Expenditure Surveys use the spending unit as the unit of analysis, and the 1990 and 1992 Surveys use the household as the unit of analysis. From the early surveys, I use cases where the spending unit is an economic family, and is the only economic family in the household. From the later two surveys, I use cases where the household consists of a single economic family. Thus I end up with six comparable samples of economic families that are alone in households.

${ }^{5}$ In these data, total expenditure is calculated as the sum of the specific expenditures reported in detailed eategories. Although in the real world, total expenditure must equal net income less direct savings, in these data, respondents often round their reported incomes so that this equality often does not hold. 
and consumption. Fourth, automobile purchases are deducted, since these lumpy expenditures reflect consumption spread over many years.

An economist's definition of consumption includes consumption flows from durable investments. Although data on most durables are not available in the Family Expenditure Surveys, there is information on two of the most expensive types of consumer durables: houses and cars. I calculate imputed durable consumption flows from automobiles and owned accommodation, and denote this as durable consumption. ${ }^{6}$ I then define imputed consumption as the sum of durable consumption and nondurable consumption. Imputed consumption may give a better indicator of well-being than total expenditure because lumpy expenditures are smoothed out. Further, with accessible and efficient capital markets, forwardlooking individuals will attempt to smooth their consumption flows over a possibly fluctuating income path. Thus, within-period imputed consumption offers an indicator of lifetime wealth.

Individual access to resources is determined by economic variables at the family level because families are the primary spending unit. However, the value of family resources to an individual family member is crucially conditioned by the characteristics of the family, especially the size of the family. ${ }^{7}$ Thus, we need an equivalence scale to deflate family income and consumption levels to individual equivalent income and consumption levels which are comparable across individuals living in families of different sizes.

I deflate family variables by an equivalence scale equal to the square root of the number of family members. This equivalence scale lies roughly in the middle of the range of scales surveyed by Buhmann et al. (1987), is the same as that used by Atkinson (1994) in his study of income inequality in Europe, and is close to the scale function estimated in Pendakur (1994). Each individual in a family is assigned income or consumption equal to the total family income or consumption divided by the equivalence scale value. The FES data are weighted at the level of the family, so each individual in a family is assigned the family weight.

\section{Family Income and Consumption Inequality During the Period 1978 Tо 1992}

\section{V.1. Mean, Medians and Shares}

Table 1 reports several indicators of the real levels and dispersions in four measures of individual well-being: equivalent family gross income, net income,

${ }^{6} I$ calculate the imputed consumption flow from accommodation as follows. For all families whose primary tenure was rental, the estimated consumption flow from housing is simply equal to rent expenditures. For all other families, the estimated consumption flow from housing is equal to the family's predicted rent from OLS regressions (by city and year) of rent on numbers of bedrooms and bathrooms. The calculation of estimated consumption flows from automobiles is slightly more complicated than that for shelter because poorer families both buy cheaper cars and buy them less often. I ran probit regressions (by city and year) of a car purchase indicator on family size, net income and net income squared to get predicted probabilities of auto purchase for all families that reported automobile operation expenses in excess of one hundred dollars. These probabilities were then multiplied by predicted purchase prices from OLS regressions for car purchasers (by city and year) of car purchase expenditures on family size, net income and net income squared.

${ }^{7}$ Characteristics other than family size, such as age, sex and disability status, may be important to the utility generated by household expenditure and income. Unfortunately, the FES data do not have details on these variables in all the sample periods. 
TABLE 1

INCOME AND CONSUMPTION INEQUALITY OVER THE 1980s

\begin{tabular}{|c|c|c|c|c|c|c|}
\hline & 1978 & 1982 & 1984 & 1986 & 1990 & 1992 \\
\hline \multicolumn{7}{|l|}{ A: Gross Income } \\
\hline Mean (1986\$) & $\$ 23,107$ & $\$ 23,486$ & $\$ 23,621$ & $\$ 25,086$ & $\$ 26,601$ & $\$ 24,957$ \\
\hline Median (1986\$) & $\$ 21,029$ & $\$ 21,364$ & $\$ 21,319$ & $\$ 22,550$ & $\$ 23,795$ & $\$ 22,187$ \\
\hline Bottom twentieth share $(\%)$ & 1.3 & 1.2 & 1.1 & 1.1 & 1.1 & 1.1 \\
\hline Bottom fifth share $(\%)$ & 8.4 & 7.8 & 7.3 & 7.3 & 7.6 & 7.1 \\
\hline Top fifth share $(\%)$ & 35.9 & 37.0 & 37.4 & 38.3 & 37.8 & 38.7 \\
\hline Top twentieth share $(\%)$ & 12.2 & 12.8 & 13.0 & 14.4 & 13.3 & 14.0 \\
\hline Gini coefficient & 0.272 & 0.289 & 0.299 & 0.308 & 0.299 & 0.316 \\
\hline Standard error & 0.0028 & 0.0028 & 0.0034 & 0.0044 & 0.0035 & 0.0036 \\
\hline Gini EDE (Sen index) & $\$ 16,822$ & $\$ 16,699$ & $\$ 16,558$ & $\$ 17,360$ & $\$ 18,647$ & $\$ 17,071$ \\
\hline \multicolumn{7}{|l|}{ B: Net Income } \\
\hline Mean $(1986 \$)$ & 19,038 & 19,345 & 19,365 & 20,101 & 20,869 & 19,632 \\
\hline Median $(1986 \$)$ & 17,557 & 17,792 & 17,738 & 18,344 & 19,059 & 17,760 \\
\hline Bottom twentieth share $(\%)$ & 1.5 & 1.5 & 1.4 & 1.4 & 1.4 & 1.4 \\
\hline Bottom fifth share $(\%)$ & 9.5 & 8.9 & 8.5 & 8.4 & 8.8 & 8.4 \\
\hline Top fifth share $(\%)$ & 34.3 & 35.1 & 35.4 & 36.2 & 35.6 & 36.3 \\
\hline Top twentieth share $(\%)$ & 11.4 & 11.9 & 11.9 & 13.1 & 12.1 & 12.5 \\
\hline Gini coefficient & 0.246 & 0.260 & 0.268 & 0.276 & 0.266 & 0.278 \\
\hline Standard error & 0.0027 & 0.0025 & 0.0030 & 0.0040 & $0.003 I$ & 0.0031 \\
\hline Gini EDE (Sen index & $\$ 14,354$ & $\$ 14,316$ & $\$ 14,175$ & $\$ 14,553$ & $\$ 15,318$ & $\$ 14,175$ \\
\hline \multicolumn{7}{|l|}{$\mathrm{C}$ : Nondurable Consumption } \\
\hline Mean $(1986 \$)$ & $\$ 12,873$ & $\$ 12,399$ & $\$ 12,632$ & $\$ 13,257$ & $\$ 13,359$ & $\$ 12,636$ \\
\hline Median $(1986 \$)$ & $\$ 12,017$ & $\$ 11,575$ & $\$ 11,621$ & $\$ 12,307$ & $\$ 12,346$ & $\$ 11,632$ \\
\hline Bottom twentieth share $(\%)$ & 1.6 & 1.6 & 1.5 & 1.5 & 1.5 & 1.5 \\
\hline Bottom fifth share $(\%)$ & 10.0 & 9.7 & 9.2 & 9.0 & 9.5 & 9.0 \\
\hline Top fifth share $(\%)$ & 33.1 & 33.6 & 34.2 & 34.9 & 34.6 & 34.8 \\
\hline Top twentieth share $(\%)$ & 10.9 & 11.0 & 11.3 & 12.3 & 11.7 & 11.9 \\
\hline Gini coefficient & 0.228 & 0.238 & 0.249 & 0.259 & 0.249 & 0.257 \\
\hline Standard error & 0.0026 & 0.0024 & 0.0028 & 0.0030 & 0.0029 & 0.0028 \\
\hline Gini EDE (Sen index) & $\$ 9,938$ & $\$ 9,448$ & $\$ 9,487$ & $\$ 9,823$ & $\$ 10,033$ & $\$ 9,389$ \\
\hline \multicolumn{7}{|l|}{ D: Imputed Consumption } \\
\hline Mean $(1986 \$)$ & $\$ 17,424$ & $\$ 16,807$ & $\$ 17,003$ & $\$ 18,098$ & $\$ 18,199$ & $\$ 17,405$ \\
\hline Median $(1986 \$)$ & $\$ 16,431$ & $\$ 15,894$ & $\$ 16,076$ & $\$ 17,115$ & $\$ 16,973$ & $\$ 16,343$ \\
\hline Bottom twentieth Share $(\%)$ & 1.8 & 1.8 & 1.8 & 1.7 & 1.8 & 1.7 \\
\hline Bottom fifth share (\%) & 10.4 & 10.2 & 10.1 & 9.9 & 10.3 & 9.9 \\
\hline Top fifth share $(\%)$ & 32.4 & 32.6 & 32.7 & 32.9 & 33.0 & 33.1 \\
\hline Top twentieth share $(\%)$ & 10.7 & 10.6 & 10.7 & 11.0 & 10.9 & 10.8 \\
\hline Gini coefficient & 0.218 & 0.223 & 0.225 & 0.231 & 0.224 & 0.231 \\
\hline Standard error & 0.0025 & 0.0022 & 0.0026 & 0.0026 & 0.0027 & 0.0024 \\
\hline Gini EDE (Sen index) & $\$ 13,623$ & $\$ 13,066$ & $\$ 13,183$ & $\$ 13,913$ & $\$ 14,117$ & $\$ 13,380$ \\
\hline
\end{tabular}

Notes: All variables are adjusted for family size with an equivalence scale equal to the square root of the number of family members. Asymptotic standard errors for the Gini coefficients are estimated following Barrett and Pendakur, 1995.

The Sen Index equals the mean minus the mean times the Gini Coefficient.

nondurable consumption and imputed consumption. All measures are reported in constant 1986 dollars and refer to family measures that have been deflated by an equivalence scale equal to the square root of the number of economic family members.

Not surprisingly, due to the effects of income taxes, mean equivalent gross income is greater in each year than mean equivalent net income. In real terms, 
between 1978 and 1990 (two non-recession years), average gross income rose by about 15 percent, but the median gross income rose by only 13 percent. Over the same period, mean and median net income rose by about 9 percent each. The paths of mean nondurable and imputed consumption given in Table 1 are relatively flatter between 1978 and 1992 than either income measure. Whereas average gross and net incomes grew considerably over the period, average nondurable and imputed consumption grew more slowly. In real terms, between 1978 and 1990 (two pre-trough years), mean nondurable consumption and mean imputed consumption grew by about 4 percent each. Median nondurable and imputed consumption levels grew slower still. That medians grew more slowly than means suggests that distributions widened over the period.

Looking at the income shares presented in the middle of each panel of Table 1, we see that gross income seems to be distributed less equally than net income: gross income shares for the bottom 5 percent and 20 percent of the population are smaller than net income shares, and gross income shares for the top 5 percent and 20 percent are larger than net income shares in every survey year. This is consistent with what we would expect to find under a progressive income tax system, where resources are taken from higher income families at a greater rate than from poorer families, and, presumably, a net transfer is made from richer to poorer families. We see a similar indication that net income is distributed less equally than nondurable consumption and that nondurable consumption is distributed less equally than imputed consumption. This relationship between the distributions of net income and consumption is consistent with the model given in Section II since some of the observed variation in incomes may be due to transitory fluctuations. The message from the shares is that gross income was distributed less equally than net income and that both of these income measures were distributed less equally than nondurable or imputed consumption. However, because shares change unevenly over time, it is difficult to use share data to track inequality over time; a summary statistic is needed.

\section{V.2. Gini Coefficients}

To examine distributional change over time, I use the Gini Coefficient of relative inequality, which measures the area between a Lorenz curve and the fortyfive degree line (the line of complete equality) on a Lorenz diagram. Estimated Gini Coefficients are shown at the bottom of each panel of Table 1, with asymptotic standard errors shown below (estimated following Barrett and Pendakur, 1995). Figure 1 shows the Gini Coefficients for income and consumption between 1978 and 1992, in absolute terms (left panel) and indexed to values in 1978 (right panel). As noted above, a relative inequality index is particularly appropriate when preferences are assumed to be CRRA and all agents are the same age. In this case, since relative inequality indices are insensitive to proportionate changes in a distribution, the Gini Coefficient for consumption inequality is equal to the Gini Coefficient for life-time wealth inequality.

V.2(i) Gross Income, Net Income and Nondurable Consumption

Between the two pre-trough years, 1978 and 1990, the Gini Coefficient for gross income increased by 2.7 percentage points, a proportionate increase of about 


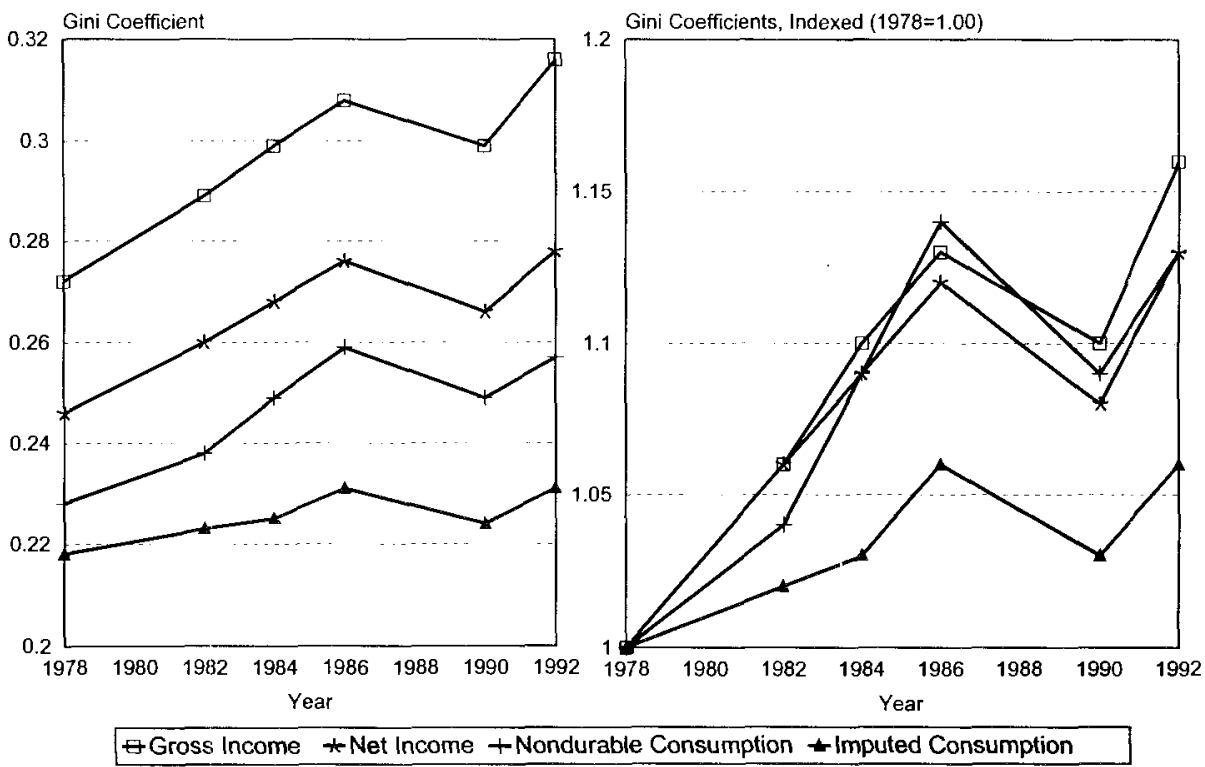

Figure 1. Gini Coefficients (Income and Consumption, 1978 92)

one tenth. ${ }^{8}$ Within this period, inequality peaked in 1986, 3.6 percentage points higher than in 1978. Between 1990, the last non-recession year, and 1992, the first year of the early 1990s recession, the Gini Coefficient for gross income inequality rose by almost two percentage points. Thus between 1978, the year with the most equally distributed gross income, and 1992, the year with the least equally distributed gross income, the Gini Coefficient on gross income rose by almost four and one-half percentage points. The estimated standard errors show that the pattern of these findings is statistically significant. There was a significant rise to 1986, a fall to 1990 , and a subsequent rise to 1992 . Further, the large increase in inequality between the two pre-trough years of 1978 and 1990 suggests that there was an upward trend in gross income inequality.

The finding of increasing trend family gross income inequality during the period 1978 to 1992 extends Wolfson's (1987) picture of increasing inequality in the early 1980s. The results in Table 1 suggest that earlier findings of lower inequality in the late 1980s than the early 1980s (McWatters and Beach, 1990; Blackburn and Bloom, 1994) may have been catching cyclical effects. The equalizing pattern between 1986 and 1990 was of comparatively small magnitude, and was entirely reversed between 1990 and 1992 .

This pattern of roughly countercyclical and trend-increasing inequality recurred in the distributions of net income and nondurable consumption between 1978 and 1992. These distributions grew much more unequal between 1978 and

${ }^{x}$ Since Gini Coefficients are quite sluggish, a two or three point difference in Gini Coefficients is quite a large difference. For example, Smeeding's (1991) analysis of Luxumbourg Income Study (LIS) data finds that Gini Coefficients for the distribution of disposable income differ by only seven points between the United States (the highest inequality nation in the LIS) and Sweden (the lowest inequality nation in the LIS). 
1986, then equalized somewhat to 1990 (but not enough to return to 1978 inequality levels), and then became much less equal to 1992. Indeed, the sizes of the relative changes in the Gini Coefficients (shown on the right side of Figure 1) are very similar for these three measures. The path of imputed consumption inequality, on the other hand, is somewhat different.

\section{V.2(ii). Imputed Consumption}

As with the Gini Coefficient for gross income, net income, and nondurable consumption, the Gini Coefficient for imputed consumption shows inequality rising between 1978 and 1986, falling to 1990 and rising again to 1992 . However, the proportional changes shown in Figure 1 suggest that the relative size of these changes were much smaller for imputed consumption than for the other three measures. Whereas the Gini Coefficients for gross income, net income and nondurable consumption inequality rose by about one-tenth between 1978 and 1990 (pre-trough years), the Gini Coefficient for imputed consumption inequality rose by only about one twenty-fifth over this period.

Imputed consumption, which is equal to rental flows plus nondurable consumption, is more equally distributed than nondurable consumption. One might think that better-off families would consume both more durables and more expensive durables, which would make imputed consumption less equally distributed. However, because the only durables for which I impute a rental flow are vehicle purchases and accommodation, this is not the case. Table 2 presents information on means, medians, quantile shares and Gini Coefficients for durable consumption, the imputed consumption flow from vehicle purchase and housing, and information on the relationship between durable consumption and nondurable consumption. Three processes occur simultaneously during 1978 to 1992 that "add up" to imputed consumption inequality rising slowly compared to nondurable consumption inequality or income inequality.

First, the Gini Coefficient on durable consumption appears to move in a procyclical fashion; durable consumption was distributed more equally during the early 1980 s recession and the early 1990 s recession than in other years. Further, the Gini Coefficient on durable consumption appears to have had a downward trend. Thus, durable consumption-an important component of imputed consumption - was equalizing over the period, and tended to equality during recessions. The addition of durable consumption to nondurable consumption moderated the cyclical changes in imputed consumption inequality and moderated the upward trend in imputed consumption inequality.

Second, the ratio of durable to nondurable consumption rose consistently during the period 1978 to 1992 . Thus, the part of imputed consumption that was equalizing formed a larger share of imputed consumption toward the end of the period. This moderated the trend towards inequality that we see in income and nondurable consumption. Third, the correlation between durable consumption with nondurable consumption rose over the period, so that better-off families were even more likely to have relatively high levels of nondurable consumption at the end of the period than at the beginning. This pushed inequality in imputed consumption upward in comparison with changes in nondurable consumption inequality. That imputed consumption inequality actually rose quite slowly and 
TABLE 2

Estimated Durabl.e Consumption

\begin{tabular}{|c|c|c|c|c|c|c|}
\hline & 1978 & 1982 & 1984 & 1986 & 1990 & 1992 \\
\hline \multicolumn{7}{|l|}{ A: Durable Consumption } \\
\hline Mean $(1986 \$)$ & $\$ 4,748$ & $\$ 4,593$ & $\$ 4,689$ & $\$ 5,170$ & $\$ 5,125$ & $\$ 5,068$ \\
\hline Median (1986\$) & $\$ 4,487$ & $\$ 4,338$ & $\$ 4,483$ & $\$ 4,874$ & $\$ 4,828$ & $\$ 4,826$ \\
\hline Bottom twentieth share $(\%)$ & 1.5 & 1.5 & 1.7 & 1.7 & 1.7 & 1.5 \\
\hline Bottom fifth share $(\%)$ & 9.6 & 9.6 & 10.7 & 10.3 & 10.7 & 10.3 \\
\hline Top fifth share $(\%)$ & 33.4 & 33.0 & 31.5 & 32.5 & 32.1 & 32.2 \\
\hline Top twentieth share (\%) & 11.2 & 10.7 & 10.3 & 10.6 & 10.5 & 10.4 \\
\hline Gini Coefficient & 0.236 & 0.233 & 0.207 & 0.221 & 0.212 & 0.217 \\
\hline Standard error & 0.0027 & 0.0022 & 0.0026 & 0.0025 & 0.0026 & 0.0025 \\
\hline \multicolumn{7}{|l|}{ B: Ratios and Correlations } \\
\hline Durable/Nondurable & 0.430 & 0.440 & 0.452 & 0.462 & 0.459 & 0.482 \\
\hline \multicolumn{7}{|l|}{ Correlation: } \\
\hline Durable vs. Nondurable & 0.590 & 0.585 & 0.630 & 0.684 & 0.650 & 0.627 \\
\hline
\end{tabular}

Note: All variables are adjusted for family size with an equivalence scale. This scale is equal to the square root of family size. Asymptotic standard errors for estinated Gini coefficients are estimated following Barrett and Pendakur, 1995. Average ratio gives the mean of (Durable Consumption/ Nondurable Consumption) computed at the individual level.

had moderated movements over the business cycle suggests that the first and second processes (which were equalizing) overpowered the disequalizing third process.

\section{V.2(iii). Social Welfare Measures}

We know that mean income and consumption grew slowly between 1978 and 1992, and that they became more unequally distributed. We may ask whether or not this growth compensated for the increased inequality. To answer this question, we can use a social welfare function defined over individual well-being measures, such as income or consumption. The Gini Equally Distributed Equivalent (Gini EDE) index is a social welfare function related to the Gini Coefficient of inequality. ${ }^{9}$ The Gini EDE index for any individual measure of well-being, such as equivalent income or consumption, is equal to the Gini Coefficient of the distribution multiplied by the mean of the distribution, and thus provides a measure of social welfare that is sensitive both to changes in the average and changes in the level of inequality. Table 1 reports Gini EDEs at the bottom of each panel. The Gini EDE for gross income was very flat between 1978 and 1984, and then went up sharply to 1990 , and dropped again during the recession in 1992. However, it was higher in 1992 than in the early 1980s. The Gini EDEs for net income, nondurable consumption and imputed consumption were much flatter over the entire period than the Gini EDE for gross income. These measures were

${ }^{9}$ A Social Welfare Function (SWF), S(u), can be defined over individual utilities, $\mathbf{u}=\left\{u_{1}, \ldots, u_{N}\right\}$. Any S-Concave and anonymous SWF (see Blackorby and Donaldson, 1984) will define concave social indifference curves over individual utility levels that are symmetric about the equality-utility ray (the 45 degree line). The Equally Distributed Equivalent (EDE) to any distribution $\hat{\mathbf{u}}$ is defined as the point where the equal utility ray intersects the social indifference curve that goes through $\hat{\mathbf{u}}$. The EDE thus measures the single utility level, which if given to all individuals, would generate social welfare equal to $S(\hat{\mathbf{u}})$, the social welfare of the actual distribution. 
similarly flat over the early 1980 s, but they underwent neither the sharp increase to 1990 , nor the large decline to 1992. If we take the Gini EDE as a measure of social welfare, and we base it on the distribution of consumption, social welfare rose very little over the 1980 s because the increase in social welfare due to slowly rising mean imputed consumption was accompanied by a decrease in social welfare due to slowly rising inequality.

Inequality rose quickly during and immediately after the early 1980 s recession, then dropped slowly between 1986 and 1990, and rose quickly again between 1990 and 1992. This pattern is consistent with countercyclical movements in family income and consumption inequality, accompanied by an upward trend. A single inequality measure such as the Gini Coefficient, however, cannot tell a very rich story about what happened. It does not tell us whether the increase in inequality happened because the rich got richer, because the poor got poorer, or both. The next subsection examines the issue of what changes in the distribution of income and consumption drove the changes in measured inequality.

\section{V.3. Quintile Means}

Figure 2 shows the changes in each quintile's mean real equivalent gross and net family income during the period 1978 to 1992, and Figure 3 shows the changes in each quintile's mean real equivalent nondurable and imputed consumption over the same period. The changes are shown in index form, with quintile means in 1978 used as the base. Figure 2 confirms that quintile mean incomes spread out over the period. However, the two recessions had very different effects on the distribution of income. The increase in inequality during and after the early 1980s recession was due to large drops in the gross and net incomes of the first and
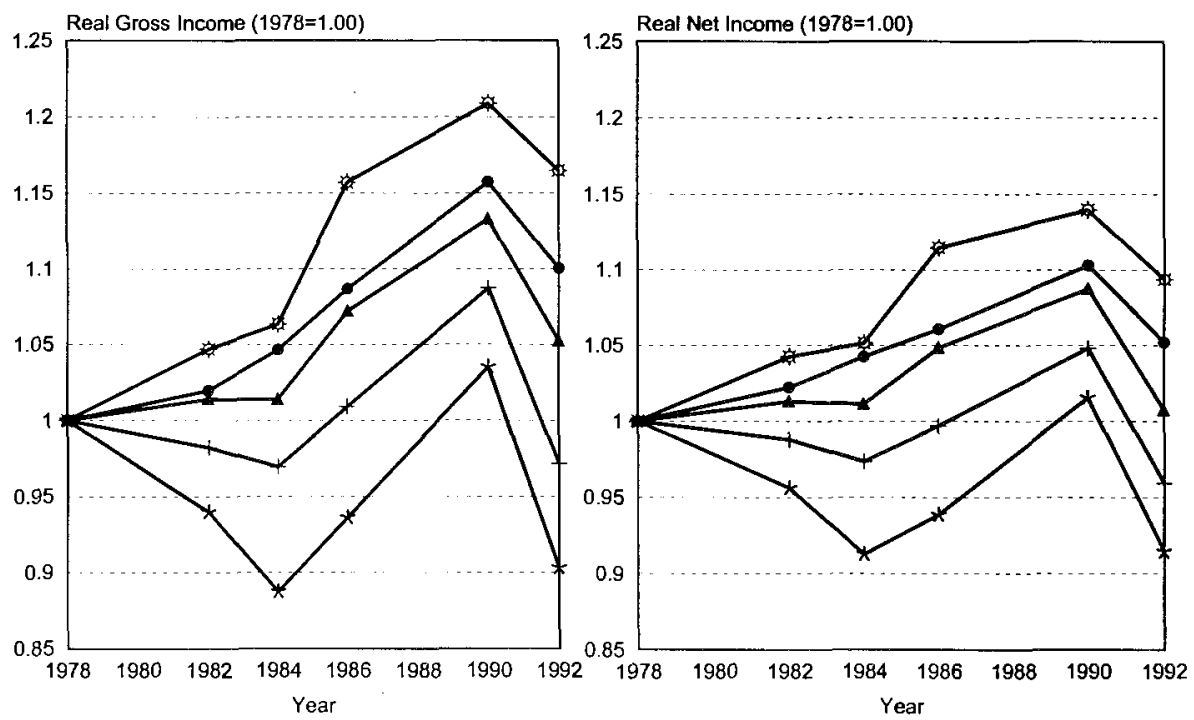

*First Quintile + Second Quintile $\star$ Third Quintile - Fourth Quintile $\$$ Fifth Quintile

Figure 2. Changes in Quantile Means (Gross Income and Net Income) 


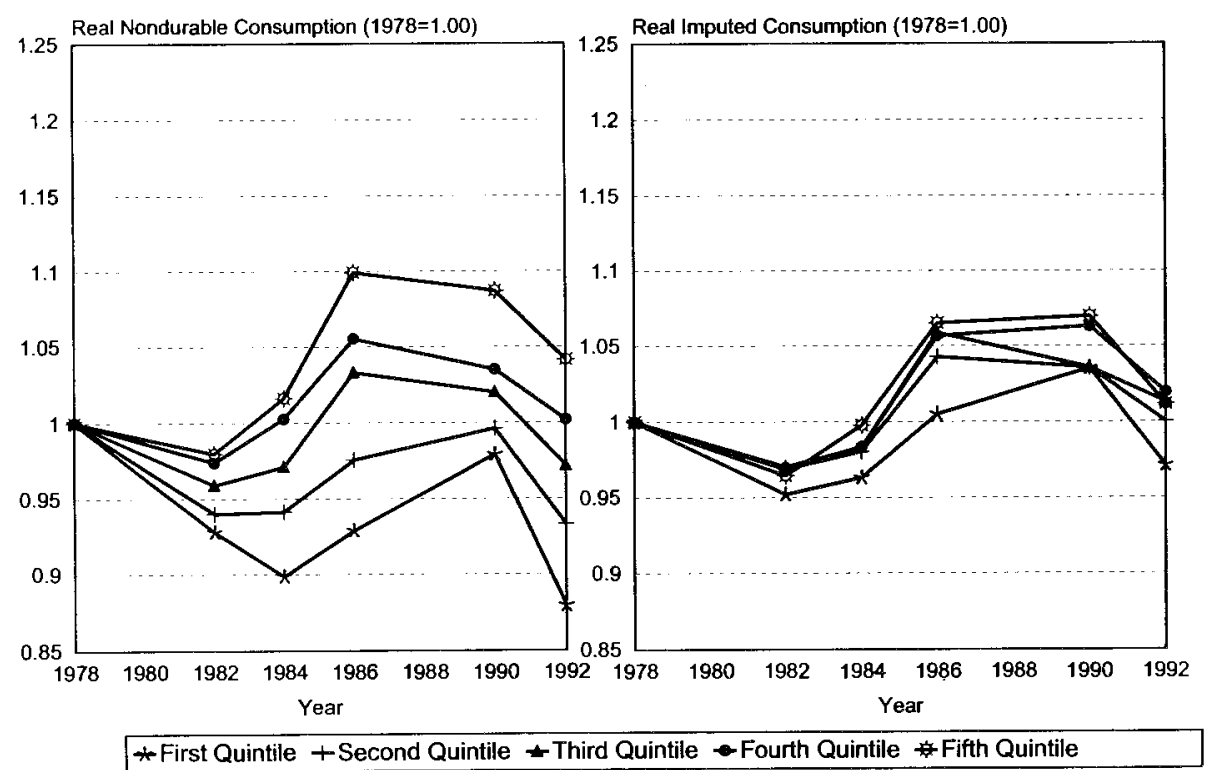

Figure 3. Changes in Quantile Means (Nondurable Consumption and Imputed Consumption)

second quintiles, accompanied by sizeable increases in the gross and net incomes of the fourth and fifth quintiles. The third quintile seems to have just held its ground between 1978 and 1984. During this period, the poorer quintiles lost income and the richer quintiles gained income, which pushed the Gini Coefficient up by over two percentage points. The smaller increase in family income inequality that we see in the early 1990s recession, on the other hand, seems to have been due to sizeable drops in the real incomes of all quintiles, wherein the bottom quintiles took the worst income shocks. Between 1990 and 1992, all income groups lost real income, but the poorer income groups lost proportionately more.

The left-hand side of Figure 3 shows the paths of quintile means for nondurable consumption and imputed consumption. The qualitative difference in the effects of the early 1990 s recession in comparison with the early 1980 s recession is not reproduced in the paths of nondurable or imputed consumption. Here, all quintiles dropped their nondurable consumption between 1978 and 1982, with poorer quintiles losing proportionately more, generating a one percentage point increase in the Gini Coefficient. ${ }^{10}$ Changes in quintile means were equalizing between 1982 and 1990 , but this equalizing process was completely reversed between 1990 and 1992 .

${ }^{10}$ That income rose while consumption fell for the upper quintiles during the 1982-84 recession might appear puzzling. The real interest rate in Canada in 1982 was around 10 percent, because nominal interest rates were still as high as 16 percent after falling from the 1981 peak, but inflation was about 6 percent over 1982 (Statistics Canada, 1991). Thus, whereas in most years direct savings accounts for about a fifth of the difference between net income and nondurable consumption for the top two quintiles, in 1982 direct savings accounted for almost 40 percent of this difference. So, the consumption declines in the upper quintiles during 1978 to 1982 may have been due to their saving behaviour, while consumption declines of the lower quintiles were probably due to their declining incomes. 
The right-hand side of Figure 3 shows quintile means for imputed consumption. We see here that the relatively small increase in imputed consumption inequality compared with changes in income and nondurable consumption inequality is due to a much smaller degree of fanning out in quintile means over the period. Changes in quintile means are bunched together throughout 1978 to 1992. Further, we can also see what made the increase in inequality during the early 1980s recession so moderate; the loss in imputed consumption between 1978 and 1982 was comparatively uniform across quintiles. Indeed, losses and gains over time were uniform across quintiles throughout the period. We do not see the pattern that emerged in quintile means for gross and net income, wherein the upper quintiles gained and the lower quintiles lost during the early $1980 \mathrm{~s}$ recession and everyone lost income during the early 1990s recession. Mean imputed consumption dropped for all quintiles during both recessions, but dropped more at the bottom.

Changes in inequality as measured by the Gini Coefficient do not seem to be due to changes in any single part of the income or consumption distribution. Some changes, such as the increase in income inequality during 1978 to 1984 , are due to the group means rising for better-off families and falling for worse-off families. Other changes, such as the increase in all types of inequality seen between 1990 and 1992, are due to group means falling in all groups, but falling proportionately more in the poorest groups. The Gini Coefficient increased, but inequality indices that are less bottom-sensitive might have shown a decrease in inequality between 1990 and 1992. The next section explores the use of inequality indices more and less bottom-sensitive than the Gini Coefficient, and asks if changing the equivalence scale changes our picture of distributional change over the 1980s.

\section{Robustness to Choice of Equivalence Scale and INEQUALITY MEASURE}

\section{VI.1. Choice of Equivalence Scale}

Phipps (1993) among others has shown that the choice of equivalence scale is important to the analysis of inequality and poverty because conclusions can easily be changed or even reversed depending on which scale is used. In this section, I consider two alternative equivalence scales to the square root of family size. First, I consider as a lower bound an equivalence scale equal to unity for all families, which leaves us with total family consumption. This undoubtedly provides an overestimate of effective resources in large families. Second, I consider as an upper bound an equivalence scale equal to family size, which leaves us with per capita consumption. Here, the equivalence scale would almost surely underestimate effective resources in large families by positing no scale economies at all.

Table 3 shows distributional statistics for total imputed consumption, equivalent imputed consumption and per capita imputed consumption. The level of measured inequality is very sensitive to the equivalence scale used to deflate family consumption into a measure of individual access to resources. The first basic finding here is that using either of our extreme equivalence scales (total family 
TABLE 3

Imputed Consumption 1Nequality, by Equivalence Scale

\begin{tabular}{lcccccc}
\hline \hline & 1978 & 1982 & 1984 & 1986 & 1990 & 1992 \\
\hline A: Total Imputed Consumption & & & & & & \\
Mean (1986\$) & $\$ 28,795$ & $\$ 27,325$ & $\$ 27,732$ & $\$ 29,854$ & $\$ 29,215$ & $\$ 27,810$ \\
Median (1986 \$) & $\$ 27,541$ & $\$ 25,804$ & $\$ 25,958$ & $\$ 27,962$ & $\$ 27,458$ & $\$ 25,918$ \\
Bottom twentieth share (\%) & 1.3 & 1.2 & 1.2 & 1.2 & 1.3 & 1.3 \\
Bottom fifth share (\%) & 8.4 & 8.1 & 8.1 & 7.7 & 8.4 & 8.0 \\
Top fifth share (\%) & 34.5 & 35.1 & 34.9 & 35.8 & 34.8 & 35.5 \\
Top twentieth share (\%) & 11.2 & 11.4 & 11.4 & 12.2 & 11.4 & 11.6 \\
Gini coefficient & 0.261 & 0.270 & 0.269 & 0.282 & 0.264 & 0.276 \\
Siandard error & 0.0027 & 0.0025 & 0.0029 & 0.0030 & 0.0029 & 0.0027 \\
Gini EDE (Sen index) & $\$ 21,291$ & $\$ 19,940$ & $\$ 20,262$ & $\$ 21,436$ & $\$ 21,493$ & $\$ 20,132$ \\
B: Per Capita 1mputed Consumption & & & & & \\
Mean (1986 \$) & $\$ 1,366$ & $\$ 11,137$ & $\$ 11,238$ & $\$ 11,878$ & $\$ 12,165$ & $\$ 11,641$ \\
Median (1986 \$) & $\$ 9,900$ & $\$ 9,839$ & $\$ 9,848$ & $\$ 10,515$ & $\$ 10,750$ & $\$ 10,431$ \\
Bottom twentieth share (\%) & 1.7 & 1.7 & 1.6 & 1.6 & 1.7 & 1.7 \\
Bottom fifth share (\%) & 9.6 & 9.6 & 9.4 & 9.1 & 9.5 & 9.4 \\
Top fifth share (\%) & 36.3 & 36.1 & 36.3 & 36.2 & 36.1 & 35.9 \\
Top twentieth share (\%) & 12.7 & 12.5 & 12.5 & 12.6 & 12.6 & 12.2 \\
Gini coefficient & 0.266 & 0.263 & 0.266 & 0.269 & 0.265 & 0.262 \\
Siandard error & 0.0030 & 0.0025 & 0.0030 & 0.0029 & 0.0032 & 0.0027 \\
Gini EDE (Sen index) & $\$ 8,343$ & $\$ 8,211$ & $\$ 8,246$ & $\$ 8,683$ & $\$ 8,936$ & $\$ 8,595$ \\
\hline
\end{tabular}

Note: Asymptotic standard errors for estimated Gini coefficients are estimated following Barrett and Pendakur, 1995.

The Sen Index equals the mean minus the mean times the Gini Coefficient.

measures or per capita measures) increases the estimated level of inequality. Estimated Gini Coeficients for total imputed consumption and per capita imputed consumption are higher in every year than they are in any year for equivalent imputed consumption. However, when we look at the quantile shares, it seems that different processes are creating the higher levels of inequality. When we use total family measures instead of equivalent measures, the bottom quantiles have smaller shares and the top quantiles have larger shares, leading to higher Gini Coefficient values. When we use per capita measures instead of equivalent measures, the upper quantiles have larger shares, and the middle groups have smaller shares, which also leads to higher Gini Coefficient values.

Apart from the level differences in measured inequality that occur when we change between family measures, equivalent measures, and per capita measures, there seems also to be a difference in the pattern over time. While the Gini Coefficients for total imputed consumption and equivalent imputed consumption share the same trend, rising through the mid-1980s, dropping to 1990 and then rising again to 1992, the Gini Coefficient for per capita imputed consumption looks very flat and even drops slightly to 1992 . However, while the standard errors reported in Table 3 suggest that the rise, fall, and rise in the Gini Coefficients for total and equivalent imputed consumption are statistically significant, the decline in the Gini Coefficient for per capita imputed consumption between 1986 and 1992 is not statistically significant. Indeed, one cannot reject the (multiple linear) hypothesis at the 5 percent level that the Gini Coefficient for per capita imputed consumption was unchanging over the six sample periods. 
Per capita measures generate flat Gini Coefficients over the six sample periods, while equivalent and total measures show large changes in inequality for two reasons. First, the changes in quantile shares are somewhat smaller for per capita measures than for the other two measures, so that Gini Coefficients are reflecting smaller changes in Lorenz curves. Second, changes in per capita imputed consumption quantile shares tend to offset each other; both better-off and worse-off groups decreased their imputed consumption shares (and middle groups gained) during the two recessions, and both the top and bottom ends improved their positions during 1986 to 1990 . For equivalent and total measures, on the other hand, the upper groups gained while bottom groups lost consumption shares during both recessionary periods.

That changes in the distribution of per capita consumption were offsetting in terms of their effects on the Gini Coefficient raises the issue of whether or not inequality indices more sensitive to different parts of the distribution indicate similar patterns of inequality change over time. The next subsection explores the degree to which using inequality indices with different degrees of bottom- or topsensitivity changes our picture of changing income and consumption inequality.

\section{VI.2. Choice of Inequality Measure}

It is well known that different inequality measures can give different stories of economic inequality (see Wolfson, 1994 or Atkinson, 1970). Only when one Lorenz curve lies entirely inside another Lorenz curve will all relative inequality indices (dual to S-Concave social welfare functions) be in agreement as to how to rank distributions (Atkinson, 1970; Donaldson and Weymark, 1980). Any

TABLE 4

Lorenz Dominance Comparisons, Income and Consumption

\begin{tabular}{|c|c|c|c|c|c|c|c|c|c|c|c|c|}
\hline 1978 & 1982 & 1984 & 1986 & 1990 & 1992 & & 1978 & 1982 & 1984 & 1986 & 1990 & 1992 \\
\hline \multicolumn{6}{|c|}{ A: Gross Income } & \multicolumn{7}{|c|}{ B: Net Income } \\
\hline 1978 & $+^{*}$ & $+^{*}$ & $t^{*}$ & $+^{*}$ & $+{ }^{*}$ & 1978 & & $+^{*}$ & $+^{*}$ & $+^{*}$ & $+^{*}$ & $+^{*}$ \\
\hline 1982 & & + & $+^{*}$ & + & $+^{*}$ & 1982 & & & + & $+^{*}$ & + & $+^{*}$ \\
\hline 1984 & & & + & $?$ & $+{ }^{*}$ & 1984 & & & & + & $?$ & $?$ \\
\hline 1986 & & & & - & $?$ & 1986 & & & & & - & $?$ \\
\hline 1990 & & & & & $+^{*}$ & 1990 & & & & & & + \\
\hline 1992 & & & & & & 1992 & & & & & & \\
\hline \multicolumn{6}{|c|}{ C: Nondurable Consumption } & \multicolumn{7}{|c|}{ D: Imputed Consumption } \\
\hline 1978 & + & $+^{*}$ & $+^{*}$ & $+^{*}$ & $+^{*}$ & 1978 & & $?$ & $+^{*}$ & $+^{*}$ & + & $+^{*}$ \\
\hline 1982 & & + & $+^{*}$ & + & $+^{*}$ & 1982 & & & + & $+^{*}$ & $?$ & + \\
\hline 1984 & & & $?$ & $?$ & $?$ & 1984 & & & & + & $?$ & $?$ \\
\hline 1986 & & & & $?$ & - & 1986 & & & & & $?$ & - \\
\hline 1990 & & & & & + & 1990 & & & & & & $?$ \\
\hline 1992 & & & & & & 1992 & & & & & & \\
\hline
\end{tabular}

Notes: All variables are adjusted for family size with an equivalence scale equal to the square root of the number of family members. A "+" signifies that the column year Lorenz dominates the row year; A " - " signifies that the column year is dominated by the row year; A "?" signifies that the Lorenz curves for the column and row years cross. For comparisons where Lorenz curves do not cross ("+" and "-"), statistical significance at the $5 \%$ level is denoted with "*". Joint confidence intervals for Lorenz curves are computed and tests for dominance conducted following Beach and Richmond, 1985. 
TABLE 5

INCOME AND CONSUMPTION INEQUALITY, BY INEQUAITTY INDEX

\begin{tabular}{lcccccc}
\hline & 1978 & 1982 & 1984 & 1986 & 1990 & 1992 \\
\hline A: Gross Income & & & & & & \\
Mean (I986 \$) & $\$ 23,107$ & $\$ 23,486$ & $\$ 23,621$ & $\$ 25,086$ & $\$ 26,601$ & $\$ 24,957$ \\
S-Gini (top sensitive) & 0.080 & 0.086 & 0.088 & 0.094 & 0.089 & 0.095 \\
Standard crror & 0.0010 & 0.0013 & 0.0013 & 0.0020 & 0.0013 & 0.0015 \\
Gini coeff. (middle sensitive) & 0.272 & 0.289 & 0.299 & 0.308 & 0.299 & 0.316 \\
Standard error & 0.0028 & 0.0028 & 0.0034 & 0.0044 & 0.0035 & 0.0036 \\
S-Gini (bottom sensitive) & 0.580 & 0.606 & 0.627 & 0.631 & 0.619 & 0.640 \\
Standard error & 0.0047 & 0.0040 & 0.0046 & 0.0047 & 0.0049 & 0.0043 \\
B: Imputed Consumption & & & & & & \\
Mean (I986 \$) & $\$ 17,424$ & $\$ 16,807$ & $\$ 17,003$ & $\$ 18,098$ & $\$ 18,199$ & $\$ 17,405$ \\
S-Gini (top sensitive) & 0.065 & 0.066 & 0.068 & 0.069 & 0.067 & 0.068 \\
Standard error & 0.0009 & 0.0008 & 0.0009 & 0.0009 & 0.0009 & 0.0008 \\
Gini coeff. (middle sensitive) & 0.218 & 0.223 & 0.225 & 0.231 & 0.224 & 0.231 \\
Standard error & 0.0025 & 0.0022 & 0.0026 & 0.0026 & 0.0027 & 0.0024 \\
S-Gini (bottom sensitive) & 0.490 & 0.500 & 0.514 & 0.520 & 0.498 & 0.507 \\
Standard error & 0.0045 & 0.0039 & 0.0047 & 0.0041 & 0.0048 & 0.0041 \\
\hline
\end{tabular}

Notes: All variables are adjusted with an equivalence scale equal to the square root of family size. Asymptotic standard errors for the S-Gini relative inequality indices (including the Gini Coefficient) are estimated following Barrett and Pendakur, 1995.

distribution whose Lorenz curve lies entirely inside a second distribution's Lorenz curve is said to "Lorenz Dominate" the second distribution. Table 4 shows Lorenz Dominance rankings for the distributions of income and consumption over the period 1978 to 1992 . Lorenz Dominance rankings that are statistically significant at the 5 percent level are denoted by "**" (hypothesis tests are conducted following Beach and Richmond, 1985). The results in Table 4 indicate that several Lorenz Dominance rankings are possible, but far fewer are available for consumption distributions than for income distributions, and only about half of them are statistically significant. The results in Table 4 suggest that we can confidently say that regardless of the inequality index used, gross and net income distributions were most equally distributed in 1978 and probably least equally distributed in 1986 or 1990 . However, because for the nondurable and imputed consumption distributions so few comparisons were strictly ranked and significant, it is hard to draw conclusions for these distributions. As is sometimes the case with Lorenz Dominance rankings, we are left with an incomplete ordering.

Table 5 shows inequality index values for three members of the S-Gini family of relative inequality indices (due to Donaldson and Weymark, 1980), an index family related to a generalization of the Gini Coefficient." The Gini Coefficient is a member of the S-Gini family, and other members of the family vary in their sensitivity to inequality at the bottom of the distribution by setting a parameter (denoted $S$ ). Three members of the S-Gini family are shown in Table 4: (i) a

\footnotetext{
"Inequality indices have two advantages over Lorenz dominance criteria. First, such indices provide cardinal measures of the degree of inequality, whereas Lorenz rankings are purely ordinal. Thus, with inequality indices, we can ask how much more unequal one distribution is than another. Second, inequality indices generate complete (though not necessarily statistically significant) orderings over distributions, whereas Lorenz rankings are often incomplete.
} 
middle sensitive member, the Gini Coefficient (with $S=2$ ); (ii) a top sensitive member (with $S=1.19$ ); and (iii) a bottom sensitive member (with $S=8.4$ ). ${ }^{12}$ The S-Gini indices have a well-defined asymptotic distribution (Barrett and Pendakur, 1995), and the estimated asymptotic standard errors are given in italics under each index value.

Examination of Table 5 shows that using inequality indices, which involves explicit choice of index sensitivity, substantially increases the range of statements we can make about changes in income and consumption distributions in comparison with incomplete Lorenz Dominance rankings, which do not require explicit sensitivity choices. The basic findings from Table 1 are all robust to varying the measure of inequality, and are all statistically significant. For all four income and consumption variables, we see the pattern of first rising inequality and then falling inequality over the $1980 \mathrm{~s}$, followed by another rise in the early 1990s. In all cases, the mid-1980s increase is bigger than late 1980s decline, and for all variables except imputed consumption, the increase between 1990 and 1992 reverses the decline between 1986 and 1990. Finally, the trend increase and volatility of all three S-Gini indices for distribution of imputed consumption are smaller than those for the distributions of income and nondurable consumption. In the next section, I will briefly compare these results with similar work done on income and consumption distributions in the U.S. over the 1980s.

\section{Urban Residents vs. All Residents and Comparisons with the United States}

Table 6 shows distributional statistics for gross income and imputed consumption for the U.S. and Canada. Data on the distribution of gross income and consumption in the U.S. are taken from Cutler and Katz (1992, Table 1). Each panel of Table 6 presents the upper and lower quintile shares and estimated Gini Coefficients for the distributions. Standard errors are provided for Canadian estimates. Cutler and Katz (1992) use all residents (including non-urban residents) in their calculations, so for comparability, I do not include results for the two years when the FES was conducted in the 15 largest CMAs only. Thus, for Canada, only the 1978, 1982, 1986, and 1992 survey years are available. Further, to ensure comparability with the American results, I use the same equivalence scale as Cutler and Katz (1992). ${ }^{13}$ Panels A and D shows results for residents of

\footnotetext{
${ }^{12}$ These particular members of S-Gini family of relative inequality indices are chosen to vary the cutoff person to whom a dollar could be transferred (financed by a lump sum tax on everyone else) without changing the level of measured inequality. The Gini Coefficient (the S-Gini where $S=2$ ) is insensitive to the median person getting another dollar, but if a dollar is transferred to any person above the median, the Gini Coefficient will register more inequality. The cutoff person, to whom a dollar can be transferred without affecting the measured level of inequality, moves down the income distribution as the bottom-sensitivity parameter, $S$, grows larger. The parameter for the bottom sensitive member $(S=8.4)$ is chosen so that the cutoff person is at the 25 th percentile, and the parameter for the top sensitive member $(S=1.19)$ is chosen so that the cutoff person is at the 60 th percentile (for details about inequality index parameter choice, see Pendakur, 1995b).

${ }^{13}$ The equivalence scale used for all estimates in Table 6 is derived from the U.S. poverty lines (Cutler and Katz, 1992) and is equal to: $(0.76 *$ (number of persons aged 14 or less) $+1.00 *$ (number of persons aged 15 or more) $)^{0.61}$. This scale is very similar to the scale used in Tables $1-2$ and 45 . In fact, changing from the cquivalence scale equal to the square root of family size to the equivalence scalc given above changes estimated Gini coefficients by less than one-tenth of one percentage point in each case.
} 
TABLE 6

Gross Income and Imputed Consumption Inequality Among All Residents and Urban Residents, Canada and the United States

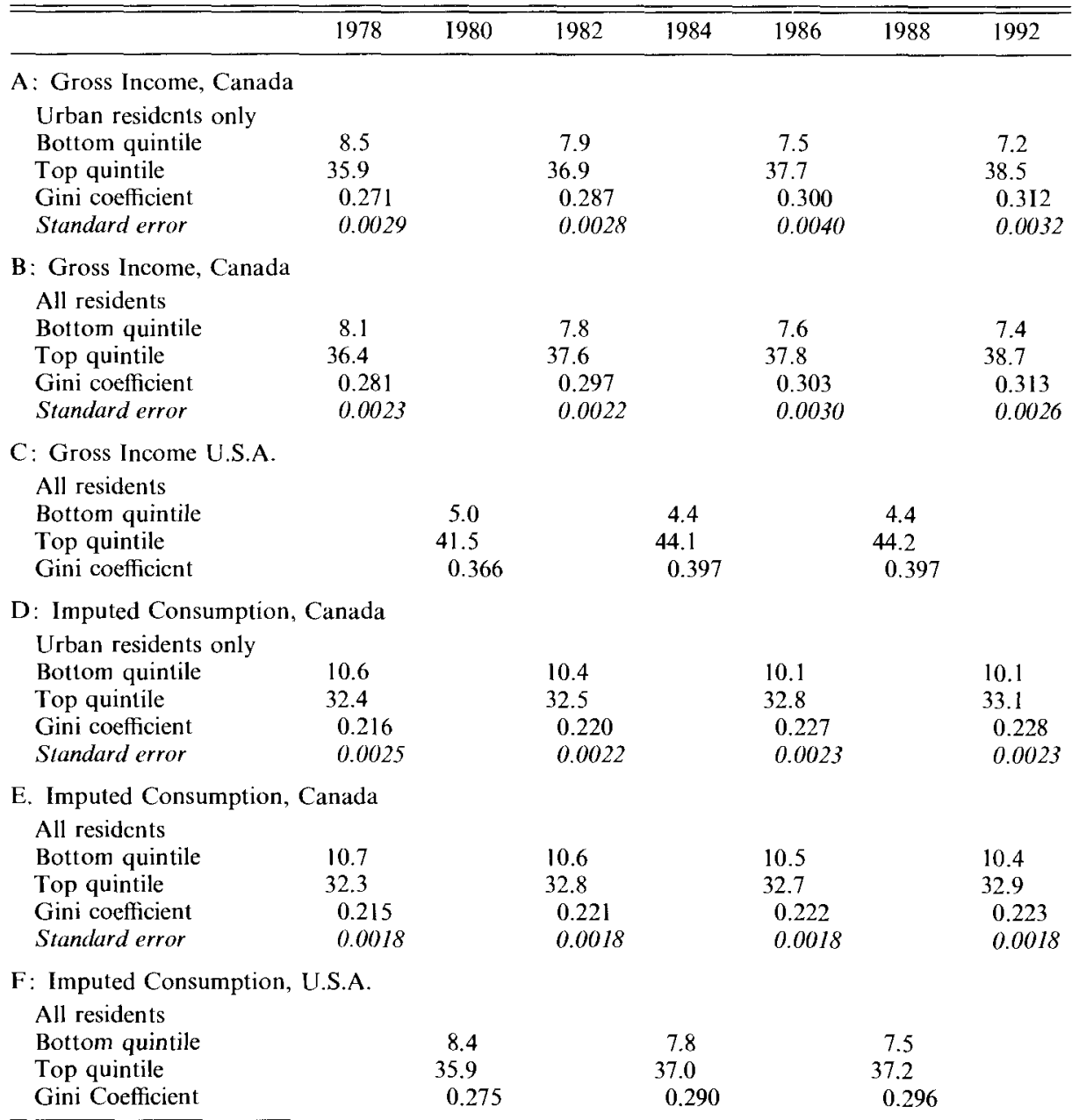

Notes: Results in Panels A and D are for residents of Canadian cities with populations greater than 100,000 (greater than 30,000 in the Atlantic Provinces).

This sample of urban residents is strictly larger than the 15 CMAs included in the preceding tables. Results shown in panels $B$ and $E$ are computed for all residents (not just urban residents) of Canada, and are comparable with Panels $\mathrm{C}$ and $\mathrm{F}$. Panels $\mathrm{C}$ and $\mathrm{F}$ are taken from Cutler and Katz, 1992, Table 1, and show results for all residents (not just urban residents) of the United States. All variables are adjusted using an equivalence scale equal to (Cutler and Katz, 1992):

$$
\left.\left(0.76^{*} \text { (number of children }\right)+1.00^{*} \text { (number of persons over I5) }\right) 0.61 \text {. }
$$

Asymptotic standard errors for Gini coefficients are estimated for following Barrett and Pendakur, 1995. 
Canada's cities, Panels B and E shows results for all (urban and non-urban) residents of Canada and panels $\mathrm{C}$ and $\mathrm{F}$ shows results for all residents of the U.S.A.

Examination of Table 6 offers four basic results. First, because Panels A and D show calculations for residents of all of Canada's cities and not just the 15 largest CMAs, I note that results for the 15 largest CMAs are not very different from results for residents of all of Canada's cities. The levels and time paths of inequality measures are the same as in Table 1.

Second, comparison of the results for Canada using residents of Canada's cities and all residents suggests that using only the CMAs does not greatly distort our picture of economic inequality in Canada. The upper and lower quintile shares are similar in size for measures based on only residents of the CMAs and measures based on all residents, and these shares follow very similar paths over time. Similarly, while the Gini coefficients based on all residents and the Gini coefficients based on residents of the CMAs seem to follow very similar paths over time. Thus, the use of only residents of the CMAs does not seem to do much violence to the data.

Third, comparison of measures based on all residents of Canada with those based on all residents of the U.S. shows that the level of inequality is much higher in all years in the U.S.A. than in all years in Canada for both gross income and imputed consumption. The estimated Gini coefficients for income are at least seven percentage points higher in the U.S.A. than in Canada in all the survey years. The estimated Gini Coefficients for imputed consumption are at least six percentage points higher in all the survey years. Estimated quintile shares are also much different across countries. The bottom quintile in Canada received less than eight percent of gross income and more than ten percent of imputed consumption, whereas in the U.S.A. the bottom quintile received less than five percent of gross income and about eight percent of imputed consumption. The upper quintile in Canada received about 37 percent of gross income and 33 percent of imputed consumption, compared to 44 percent of gross income and 37 percent of imputed consumption in the U.S.

Finally, Table 4 shows that the Gini Coefficients for inequality in the distribution of gross family income grew by about three percentage points in each country during the 1980s. On the other hand, while the Gini Coefficient for American imputed consumption inequality grew by over two percentage points, the Gini Coefficient for Canadian imputed consumption inequality grew by less than one percentage point. Thus, although the inequality in the distribution of gross income grew by about the same amount in both countries, inequality in the distribution of lifetime wealth-as measured by imputed consumption-may have changed much less in Canada than in the U.S.

\section{Discussion}

Why did income and consumption grow more unequal over the 1980s, and why did consumption inequality grow less than income inequality? While this paper cannot provide definitive answers to these questions, explanations may be based on four factors: (i) changes in the distribution of family sizes, (ii) differences 
across regions, (iii) changes in the relationship between income and consumption, and (iv) changes in the processes generating the gross income distribution.

Changes in the size composition of Canadian families may have caused changes in inequality. However, this can only have an effect on welfare measures if the researcher uses an inaccurate equivalence scale. There are two ways in which the equivalence scale could be inaccurate. Preferences may not be consistent with the use of equivalence scales, or preferences may be consistent with the use of scales, but the researcher may use the wrong scale. ${ }^{14}$ Both parametric (Blundell and Lewbel, 1994; and Van der Praag and Smolensky, 1980) and semiparametric (Pendakur, 1997) tests of the consistency of preferences with the use of equivalence scales suggest that equivalence scales are acceptable tools for making inter-household comparisons. ${ }^{15}$ However, it could still be the case that we are using the wrong equivalence scale.

The results presented in Section VI demonstrate that using either the total family measure or the family measure divided by the square root of family size gives one the same impression of the dynamics of inequality over the period: countercyclical and increasing. On the other hand, using the family measure divided by family size gives an impression of unchanging inequality over the $1980 \mathrm{~s}$. I tried a variety of equivalence scales lying between the square root of family size and just family size, and found that the dynamics in measured inequality only became insignificantly increasing (that is, flat) when I used equivalence scales that divided family income or consumption by something as large as family size raised to the power of nine-tenths. An equivalence scale which attributes scale economies this large to families consisting of more than one person lies well outside the range of those estimated by most researchers (Buhmann, et al. 1987). Thus, I do not think that changes in family size coupled with the use of the wrong equivalence scale drove changes in measured inequality.

A second explanation for changes in Canada's income and consumption distribution is a regional story. I evaluated changes in the income and consumption distributions separately for each of Canada's five regions and found that inequality levels were increasing over the period in all regions except the Prairies (Manitoba, Saskatchewan, and Alberta). In the Prairies, average income and consumption were declining, and inequality was steady. Thus, inequality was increasing in all regions except the relatively poor Prairies, so that income and consumption inequality measured at the national level grew between 1978 and 1992. Unfortunately, these findings merely push the question back a step: why did income and consumption inequality rise in each region?

\footnotetext{
${ }^{14}$ Equivalence Scale Exactness (ESE), also known as Base-Independence, is the restriction on family preferences required to use equivalence scales (see Blackorby and Donaldson, 1993, or Lewbel, 1989). The assumption of ESE requires that the true equivalence scale be invariant to income or consumption levels, which is not prima facie obvious. ESE is composed of an untestable information restriction on inter-family comparability of utility and a testable restriction on the shape of Engel curves across houscholds.

${ }^{15}$ Parametric testing by Blundel and Lewbel (1994) and Van der Praag and Smolensky (1980) suggest that deviations from Equivalence Scale Exactness (ESE) are economically insignificant, and only barely statistically significant. Semiparametric tests by Pendakur (1997) finds that ESE is only rejected for comparisons of families with children to childless families.
} 
A third hypothesis is that something is changing in the relationship between family income and family consumption. The spread between gross income inequality and imputed consumption inequality grew from five percentage points in 1978 to eight percentage points in 1992. As noted in Section V.2(ii), estimated durable consumption tended to be an equalizing component of imputed consumption, and grew as a proportion of imputed consumption over the period. Thus, we might think that shifts in consumption towards durables offset the disequalizing effects of widening income distributions. However, the fact that the distribution of nondurable consumption equalizes and disequalizes so closely with the distributions of net and gross income suggests that the normative consequences of such changes might be difficult to interpret. If we assumed, for example, that families put a constant share of their true consumption into nondurables, then nondurable consumption would be a perfect indicator of true consumption and well-being, and we would think that the distribution of well-being became much more unequal. If, on the other hand, we are confident that the imputed consumption measure is a good indicator of well-being, then we would conclude that the distribution of well-being did disequalize, but not so much as the distribution of income. The real answer probably lies somewhere in between.

The final hypothesis is that the crucial causal element lies in the determination of the gross income distribution; that is, gross family income became more unequally distributed, and so family consumption became more unequally distributed. This could be true if changes in the distribution of income were perceived as permanent, or if imperfect credit markets did not permit people to smooth their consumption over income instability. One story for why gross family income inequality grew over the 1980s has to do with worsening labor market conditions for workers at the bottom end of the skill-spectrum and the labor market. Unfortunately, the FES data used in this research do not lend themselves to inquiries based on income earner and income source, because income is not categorized by earner and source for all of the survey years. Further research is needed on the determinants of changes in the family income distribution.

\section{CONClusions}

This research extends our knowledge of the evolution of family income distribution in Canada from 1978 to 1992, and, perhaps more importantly, evaluates changes in the distribution of family consumption over this period. I find that while family incomes did equalize somewhat over the late $1980 \mathrm{~s}$, as noted by McWatters and Beach (1990); and Blackburn and Bloom (1994), this trend was entirely reversed during the early 1990s. Family income was less equally distributed in Canada in 1992 than at any time during the previous one and one-half decades. I also construct two measures of consumption inequality, and examine their distribution during the period 1978 to 1992 . I find that both nondurable and imputed consumption distributions grew more unequal over the period, but that the change for imputed consumption was less drastic. That the distribution of consumption, as opposed to income, grew more unequal over the 1980s suggests that the distribution of lifetime wealth widened over this period. This provides evidence that 
increasing inequality in income distributions has been reflected in the distribution of consumption and lifetime wealth.

The paths of inequality levels in income and consumption reveal a countercyclical pattern. Periods preceding the recessions of the early 1980s and the early 1990s were characterized by relatively low levels of inequality in all variables. Further, inequality rose sharply during both recession years, and indeed continued to rise well into the recovery after the early 1980 s recession. Comparisons with the U.S. reveal increases in income inequality of similar magnitudes in the two countries, but a much smaller increase in consumption inequality in Canada than in the U.S.

\section{REFERENCES}

Abraham, K. and S. Houseman, Earnings Inequality in Germany, NBER Working Paper Series, No. 4541, November 1993.

Atkinson, A. B., On the measurement of inequality, Journal of Economic Theory, 2, 244-63, 1970.

..... Income Inequality in OECD Countries, LIS Working Paper, 1993.

Barrett, G. and K. Pendakur, Asymptotic Distributions for the Generalized Gini Family of Inequality Indices, Canadian Journal of Economics, 28(4b), November 1995.

Beach, C. M., Cyclical Sensitivity of Aggregate Income Inequality, Review of Economic Studies, 59, $56-66,1977$.

- and J. Richmond, Joint Confidence Intervals for Income Shares and Lorenz curves, International Economic Review, 26(2), 439-50, 1985.

Blackburn, M. and D. Bloom, The Distribution of Family Income: Measuring and Explaining Changes in the 1980s for Canada and the United States, in Small Differences That Matter, Card, D. and R. Freeman (eds.), National Bureau of Economic Research, Washington, DC, 1994.

Blackorby, C. and D. Donaldson, Adult Equivalence Scales and the Economic Implementation of Interpersonal Comparisons of Well-Being, Social Choice and Welfare, 10, 335-61, 1993.

_........ Ethically Significant Ordinal Indexes of Relative Inequality, in Advances in Econometrics, 3 , $131-47,1984$.

Blundell, R. and A. Lewbel, The Information Content of Equivalence Scales, Journal of Econometrics, $50,4968,1994$.

Browing, M. and A. Lusardi, Household Savings: Micro Theories and Micro Facts, Journal of Economic Literature, 34(4), 1797-1855, December 1996.

Buhmann, B., L. Rainwater, G. Schmaus, and T. Smeeding, Equivalence Scales, Well-Being, Inequality, Review of Income and Wealth, 34, 115 42, 1987.

Buse, A., The Cyclical Behaviour of the Size Distribution of Income in Canada: 1947-78, Canadian Journal of Economics, 15(2), 189 204, 1982.

Cutler, D. and L. Katz, Rising lnequality? Changes in the Distribution of Income and Consumption in the 1980s, American Economic Review, 82(2), 546-51, 1992.

Davis, S., Cross Country Patterns of Change in Relative Wages, NBER Working Paper 4085, 1992.

Donaldson, D. and J. Weymark, A Single-Parameter Generalization of the Gini Indices of Inequality, Journal of Economic Theory, 22(1), 67-86, 1980.

Gottschalk, P., Changes in Inequality of Family Income in LIS Countries, Luxembourg Income Study Working Paper Series 66, 1991.

Gouveia, M. and J. Tavares, The Distribution of Household Income and Expenditure in Portugal: 1980 and 1990, Review of Income and Wealth, 41(1), 1-18, 1995.

Jencks, C., The Hidden Prosperity of the 1970s, Public Interest, 77, 37-61, 1984.

Karoly, L., The Trend in Inequality Among Families, Individuals and Workers in the United States: A 25-Year Perspective, in Danziger, S. and P. Gottschalk (eds.), Uneven Tides: Rising Inequality in America, Russell Sage, New York, 1992.

Lewbel, A., Household Equivalence Scales and Welfare Comparisons, Journal of Public Economics, 39, 377-91, 1989.

McWatters, C. and C. M. Beach, Factors Behind the Changes in Canada's Family Income Distribution, Relations Industrielles, 45(1), 1990.

Messinger, H., F. Fedyk, and A. Zeesman, The Size Distribution of the Poverty Gap in Canada, Review of Income and Wealth, 34(3), 275-88, 1988. 
Nelson, J., Methods of Estimating Household Equivalence Scales: An Empirical Investigation, Review of Income and Wealth, 38(3), 295-310, 1992.

Pendakur, K., Semiparametric Estimates and Tests of Base-1ndependent Equivalence Scales, Journal of Econometrics, forthcoming.

, A Method for Crossing 1nequality Index Parameters, unpublished mimeo, Department of Economics, Simon Fraser University, 1995b.

_ Estimating a Household Equivalence Scale for Canada, Department of Economics, Simon Fraser University, unpublished mimeo, 1994.

Phipps, S., Measuring Poverty Among Canadian Households, Journal of Human Resources, 28(1), $162-84,1993$.

Slesnick, D., Gaining Ground: Poverty in the Post-War United States, Journal of Political Economy, $101(1), 1-38,1993$.

Statistics Canada, Family Expenditure Survey Micro Data Tapes, Care of University of British Columbia Data Library and Simon Fraser University Data Library, 1978, 1982, 1984, 1986, 1990, and 1992.

Canadian Economic Observer, Minister of Supply and Services, Ottawa, Canada, 1991.

Van der Gaag, J. E. Smolensky, True Household Equivalence Scales and Characteristics of the Poor in the U.S.A., Review of Income and Wealth, 28(1), 17--28, 1980.

Wolfson, M., Polarization and Inequality: Methodological Issues, Statistics Canada Analytical Studies Working Paper Series, presented at American Economics Association Meetings, Boston, MA, 1994.

-, Stasis Amid Change: Income Inequality in Canada 1965-83, Review of Income and Wealth, 337-69, 1987. 